\title{
Trends in Scientific Literature on Atypical Antipsychotics in South Korea: A Bibliometric Study
}

\author{
Francisco López-Muñoz ${ }^{1,2} \bowtie$, Winston W. Shen ${ }^{3}$, Chi-Un Pae ${ }^{4,5}$, Raquel Moreno', Gabriel Rubio ${ }^{6}$, \\ Juan D. Molina ${ }^{1,7}$, Concha Noriega ${ }^{1}$, Miguel A. Pérez-Nieto', Lorena Huelves ${ }^{1}$ and Cecilio Álamo ${ }^{2}$ \\ ${ }^{1}$ Faculty of Health Sciences, Camilo José Cela University, Madrid, Spain \\ ${ }^{2}$ Department of Pharmacology, University of Alcalá, Madrid, Spain \\ ${ }^{3}$ Department of Psychiatry, Wan Fang Medical Center and School of Medicine, Taipei Medical University, Taipei, Taiwan \\ ${ }^{4}$ Department of Psychiatry, The Catholic University of Korea College of Medicine, Seoul, Republic of Korea \\ ${ }^{5}$ Department of Psychiatry and Behavioral Science, Duke University Medical Center, Durham, NC, USA \\ ${ }^{6}$ Department of Psychiatry, "Doce de Octubre" University Hospital, Complutense University, Madrid, Spain \\ ${ }^{7}$ Acute Inpatients Unit, Dr. R. Lafora Psychiatric Hospital, Madrid, Spain
}

Objective We have carried out a bibliometric study on the scientific publications in relation to atypical or second-generation antipsychotic drugs (SGAs) in South Korea.

Methods With the EMBASE and MEDLINE databases, we selected those publications made in South Korea whose title included the descriptors atypic* (atypical*) antipsychotic*, second-generation antipsychotic*, clozapine, risperidone, olanzapine, ziprasidone, quetiapine, sertindole, aripiprazole, paliperidone, amisulpride, zotepine, asenapine, iloperidone, lurasidone, perospirone and blonanserin. We applied some bibliometric indicators of paper production and dispersion with Price's law and Bradford's law, respectively. We also calculated the participation index (PI) of the different countries, and correlated the bibliometric data with some social and health data from Korea (such as total per capita expenditure on health and gross domestic expenditure on research and development).

Results We collected 326 original papers published between 1993 and 2011. Our results state fulfilment of fulfilled Price's law, with scientific production on SGAs showing exponential growth (correlation coefficient $r=0.8978$, as against an $r=0.8149$ after linear adjustment). The most widely studied drugs were risperidone (91 papers), aripiprazole (77), olanzapine (53), and clozapine (43). Division into Bradford zones yielded a nucleus occupied by the Progress in Neuro-Psychopharmacology and Biological Psychiatry (36 articles). A total of 86 different journals were published, with 4 of the first 10 used journals having an impact factor being greater than 4 .

Conclusion The publications on SGAs in South Korea have undergone exponential growth over the studied period, without evidence of reaching a saturation point.

Psychiatry Investig 2013;10:8-16

Key Words Second-generation antipsychotics, Atypical antipsychotics, Bibliometry, Schizophrenia, Bipolar disorder, South Korea.

\section{INTRODUCTION}

The main therapeutic pillar for schizophrenia during the last 60 years have been antipsychotic drugs. The so-called "psychopharmacological revolution" in the context of treating

\section{Received: June 20, 2012 Revised: July 30, 2012}

Accepted: August 1, 2012 Available online: February 8, 2013

$\triangle$ Correspondence: Francisco López-Muñoz, MD, PhD

Faculty of Health Sciences, Camilo José Cela University, C/ Castillo de Alarcón, 49, Urb. Villafranca del Castillo, 28692 Villanueva de la Cañada, Madrid, Spain

Tel: +349181531 31, Fax: +34918609343

E-mail: francisco.lopez.munoz@gmail.com

(a) This is an Open Access article distributed under the terms of the Creative Commons Attribution Non-Commercial License (http://creativecommons.org/licenses/bync/3.0) which permits unrestricted non-commercial use, distribution, and reproduction in any medium, provided the original work is properly cited. schizophrenic patients, began in the 1950s with the clinical introduction of chlorpromazine ${ }^{1,2}$ and haloperidol. ${ }^{3}$

These first drugs, called first-generation, classical or typical, biochemically characterized for blocking dopamine receptors, showed a great efficacy at reducing schizophrenia positive symptoms (hallucinations, delusion, etc.). But their main limitation is side effects, principally extrapyramidal symptoms (EPS). But after the reintroduction in the United States of clozapine, an antipsychotic drug commercialized in the 1960s, later withdrawn due to inducing agranulocytosis, ${ }^{4}$ the research expectations changed dramatically. Apart from causing few EPS, this agent showed efficacy in both positive and negative symptoms of schizophrenia as well as in patients who are refractory to other antipsychotic treatment. ${ }^{5}$ Also, this drug 
had differential pharmacological characteristics, especially at the level of the receptor blockage. Clozapine was the third cornerstone on the history of antipsychotic pharmacology, and opened the door to the so-called "atypical antipsychotics" or second-generation antipsychotic drugs (SGAs), with the introduction of risperidone in 1993.

As shown in Table 1, the advances achieved in the field of antipsychotic drugs in the past 20 years have been incredibly important, with the clinical introduction of numerous SGAs (risperidone, olanzapine, quetiapine, ziprasidone, aripiprazole, etc.). These agents have notably improved the quality of life of psychotic patients and have contributed decisively to weakening the stigmatization that has traditionally accompanied psychiatric attention. ${ }^{7}$ With the clinical introduction of the new SGAs since 1993 and, later on, with their licensing for treating bipolar disorder since 2003, research related to these drugs has advanced considerably, and this has undoubtedly translated into a considerable increase in the amount of scientific literature on these drugs-as it has been analyzed, in the specific case of Korea, in this study.

South Korea, once one of the four little Asian dragons, is

Table 1. Clinical development of second generation antipsychotics

\begin{tabular}{llll}
\hline & \multicolumn{1}{c}{ Company } & \multicolumn{2}{c}{ Launch } \\
\hline Clozapine & Wander Laboratories & $1972^{*}$ & Switzerland \\
Zotepine & Fujisawa & $1982^{\dagger}$ & Japan \\
Amisulpride & Synthelabo & 1986 & Portugal \\
Risperidone & Johnson \& Johnson & 1993 & UK/Canada \\
Sertindole & Abbott Laboratories & $1996^{\ddagger}$ & UK \\
Olanzapine & Eli Lilly & 1996 & USA/UK \\
Quetiapine & AstraZeneca & 1997 & USA/UK \\
Ziprasidone & Pfizer & 2001 & USA \\
Perospirone & Dainippon Sumitomo & 2001 & Japan \\
& Pharma & & \\
Aripiprazole & Otsuka/Bristol-Myers & 2002 & USA \\
& Squibb & & \\
Paliperidone & Janssen Pharmaceutica & 2007 & USA \\
Blonanserin & Dainippon Sumitomo & 2008 & Japan \\
& Pharma & & \\
Asenapine & Schering-Plough & 2009 & USA \\
Iloperidone & Novartis AG & 2009 & USA \\
Lurasidone & Dainippon Sumitomo & 2011 & USA \\
& Pharma & & \\
\hline & in & &
\end{tabular}

*reintroduced in 1990 in USA and UK after being withdrawn from the market in $1975,{ }^{\dagger}$ commercialized by Astellas in Germany in $1990,{ }^{ \pm}$marketing authorization was suspended by the European Medicines Agency (EMA) in 1998 and the drug was withdrawn from the market. In 2002, based on new data, the EMA suggested that sertindole could be reintroduced for restricted use, and with extensive ECG monitoring requirement now one of the great 20-50-class economic powers of East Asia, and is the most industrialised member country of the Organization for Economic and Co-operative Development (OECD). As of March 2011, South Korea (population of 50 million) has 3,122 board-certified psychiatrists (and 621 resident psychiatrists), 84 training hospitals, 171 mental hospitals (382 hospitals if including general hospitals that has psychiatry department), 861 private outpatient clinics, and 1.5 psychiatric outpatient clinics per 100,000 population. ${ }^{8}$

The number of psychiatric beds in Korea has continuously increased from the 1980s and this rate of increase is higher than in any other OECD member nation. ${ }^{9}$ The patients admitted to mental hospitals belong primarily to the diagnostic of schizophrenia (67\%)..$^{10}$ But it is problematic that patients with schizophrenia are still predominantly treated by hospitalization in Korea, and mean length of stay is greater than in other countries. The infrastructure to support the implementation of the mental health policy has yet to be strengthened. ${ }^{11}$

The use of bibliometric indicators for studying research activity in a specific country in a particular field is based on the premise that scientific publication is the essential result of such activity. ${ }^{12}$ Bibliometric studies are useful tools for assessing the social and scientific relevance of a given discipline or field. ${ }^{13}$ Our group has studied, with a bibliometric approach, the evolution of scientific literature in psychiatry by specific research groups, on different psychiatric disorders, on aspects related to the discipline, and on specific therapeutic tools in the field of psychopharmacology. ${ }^{14-19}$ Here, we specifically carried out this bibliometric study on SGA publications in South Korea.

\section{METHODS}

\section{Data collection}

The databases used in this bibliometric study were MEDLINE (Index Medicus, U.S. National Library of Medicine, Bethesda, MD, United States) and Excerpta Medica (Elsevier Science Publishers, Amsterdam, Netherlands), which are considered the most exhaustive databases in the biomedical field, and which both participate in EMBASE Biomedical Answer web (Elsevier B.V.).

With remote downloading techniques, we selected papers containing, in the author address (AD) section the descriptor South Korea, and in the TI (title) section, the descriptors atypic* (atypical*) antipsychotic*, second-generation antipsychotic*, clozapine, risperidone, olanzapine, ziprasidone, quetiapine, sertindole, aripiprazole, paliperidone, amisulpride, zotepine, asenapine, iloperidone, lurasidone, perospirone and blonanserin, published in the period from 1993 to 2011. The rest of the descriptors, referring to pharmacological aspects, 
were not restricted to any field of the database. For the purposes of this study we considered all original articles, brief articles, reviews, editorials, letters-to-the editor, etc., and all duplicated papers were omitted. In this regard, the database used permits the elimination of items that may be duplicated in each of the databases (MEDLINE and EMBASE).

With manual coding after studying the title and/or abstracts of the articles, we divided those papers into four groups: "experimental pharmacology," "clinical efficacy," "tolerance and/ or safety," and "not specified group."

\section{Bibliometric indicators}

Among the bibliometric indicators of production applied is Prices law..$^{20}$ This law is the indicator most widely used in analysing the productivity of a specific discipline or a particular country, to reflect a fundamental aspect of scientific production, which is its exponential growth. To assess whether the growth of scientific production in SGAs follows Price's law of exponential growth, we made a linear adjustment of the data obtained, according to the equation $y=3.517 \chi-17.991$, and another adjustment to an exponential curve, according to the equation $\mathrm{y}=0.089 \mathrm{e}^{0.3701 \mathrm{x}}$.

As a bibliometric indicator of the dispersion of scientific information, we used Bradford's law. ${ }^{21}$ With the aim of revealing the distribution of the scientific literature in a particular discipline, Bradford proposed a model of concentric zones of productivity (Bradford zones) with decreasing density of information. ${ }^{21}$ Thus, each zone would contain a similar number of papers, but the number of journals in which these are published would increase on passing from one zone to another. This model permits identification of the journals most widely used or with greatest weight in a given field of scientific production.

We used the impact factor (IF) ${ }^{22}$ as an indicator of the publications' repercussion. This indicator, developed by the Institute for Scientific Information (Philadelphia, Pennsylvania, USA), is published annually in the Journal Citation Reports (JCR) section of the Science Citation Index (SCI). The IF of a journal is calculated on the basis of the number of times this journals is cited in the source journals of the SCI during the two previous years and the total number of articles published by the journal in question in these two years. The JCR lists scientific journals by specific areas, ascribing to each of them their corresponding IF and establishing a ranking of "prestige."22 We used the IF data of 2010 published in the JCR of 2011.

Another indicator included in the present analysis is the national participation index (PI) of Korea for overall scientific production (the ratio of the number of papers generated by South Korea and the total number of papers on this topic).
This PI has also been compared with global PI in biomedical and health sciences (as well as for Psychiatry and Neurology area in particular). Likewise, the PI has been correlated with some health data, such as total per capita expenditure on health and gross domestic expenditure on research and development (R\&D). The PI has also been correlated with the corresponding PI for the world's 10 most productive countries during the period from 1993 to 2011. Its health data were obtained from the OECD Health Division, ${ }^{23}$ and WHO Department of Health Statistics and Informatics. ${ }^{24}$

\section{RESULTS}

After study of the analysed database, during the period from 1993 to 2011, we obtained 326 original papers (articles, reviews, editorials, letters-to-the-editor, etc.) dealing with different aspects related to SGAs in South Korea. Of these, 91 papers correspond to risperidone, 77 to aripiprazole, 53 to olanzapine, 43 to clozapine, 34 to quetiapine, 18 to ziprasidone, 14 to amisulpride, 12 to paliperidone, 3 to sertindole 2 to blonanserin, and 2 to lurasidone. We did not find any paper on zotepine, asenapine, iloperidone and perospirone was found. Perospirone is not available in Korea.

As illustrated in Figure 1, over the last 20 years there has been a marked increase in the number of SGA publications generated in South Korea on a worldwide basis. As shown in Figure 1, the mathematical adjustment to an exponential curve permitted us to obtain a correlation coefficient $\mathrm{r}=0.8978$, indicating $19.39 \%$ of variance unexplained by this fitting. In contrast, the linear adjustment of the measured values provides an $\mathrm{r}=0.8149$, and therefore a percentage of unexplained

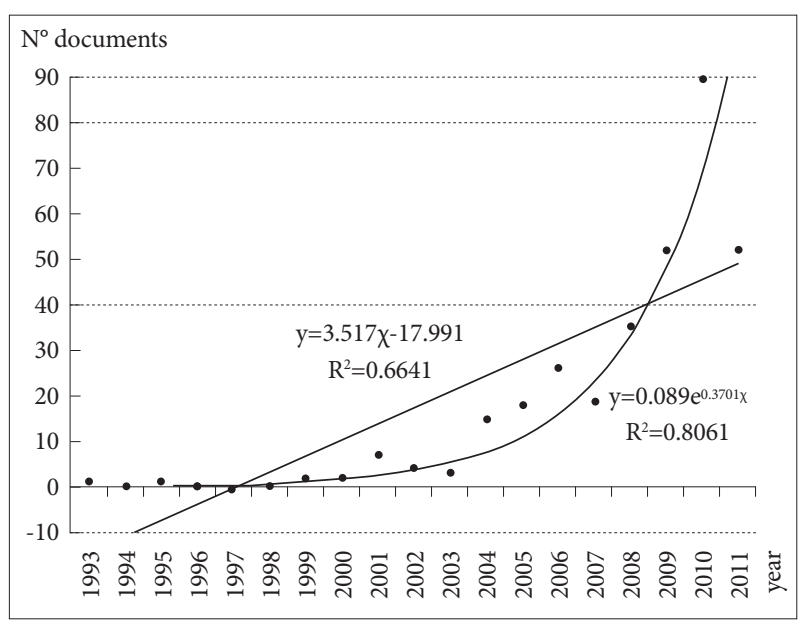

Figure 1. Growth of scientific production on second-generation antipsychotic drugs in Korea. A linear adjustment of the data was carried out, and a fitting to an exponential curve for SGA papers according to Price's law ${ }^{20}$ was found. Linear adjustment: $y=3.517 x$ $17.991\left(r^{2}=0.6641\right)$. Exponential adjustment: $y=0.089 e^{0.3701 x}\left(r^{2}=\right.$ $0.8061)$. SGA: second-generation antipsychotic drug. 


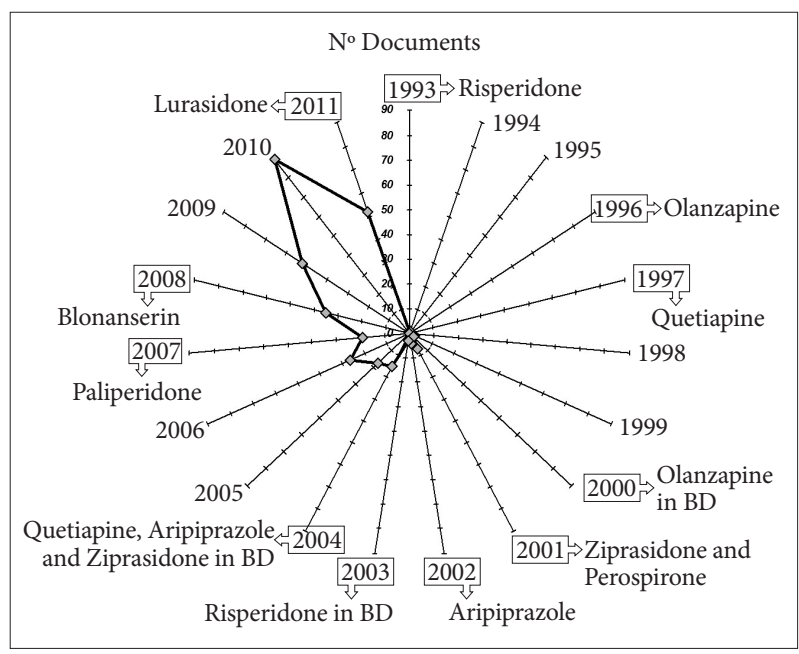

Figure 2. Number of documents on second-generation antipsychotic drugs (1993-2011) and international licensing of different drugs.

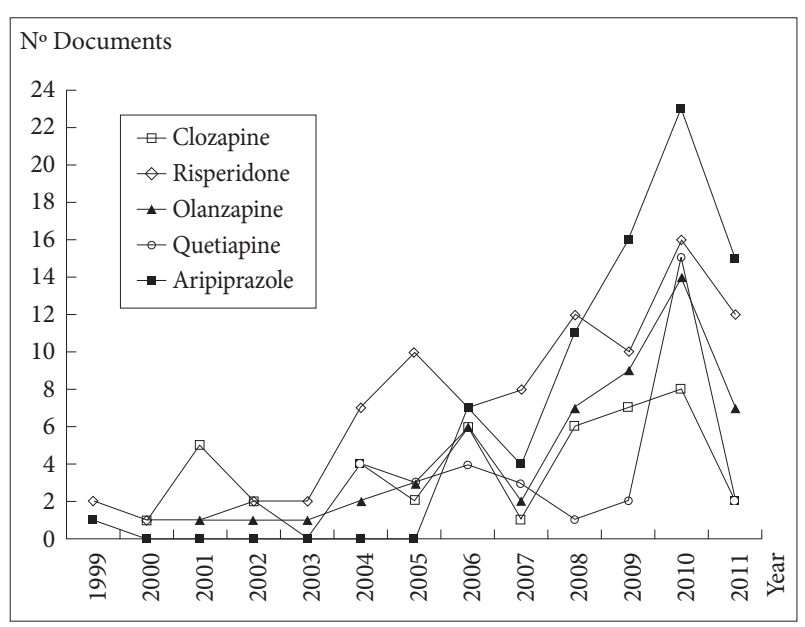

Figure 3. Evolution of scientific papers on five most relevant second-generation antipsychotic drugs (based on MEDLINE and EMBASE from 1999 to 2011).

variance of $33.59 \%$. With these data, we can conclude that the database analyzed was more in keeping with an exponential fitting than a linear one, and that the postulates of Price's law were fulfilled.

The clinical introduction of the new SGAs in different countries of the world, together with their licensing for treating bipolar disorder, is to have contributed substantially to the increase in scientific production in the SGA field in Korea, as can be seen in Figure 2. Further, Figure 3 depicts the evolution that has occurred in the last two decades of all SGA papers. With effects from 2004 and 2008, the growth was mainly due to two drugs, risperidone and aripiprazole, respectively. Figure 4 illustrates the matter even better, by showing that cumulative growth in total SGA scientific production in Korea was increased in each five-year period compared to the previous one with even gradual increment. This growth was always

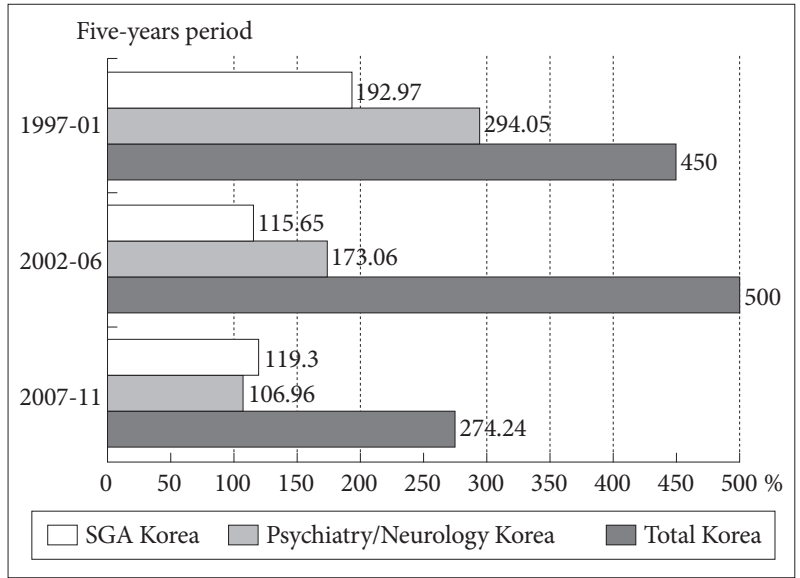

Figure 4. Cumulative growth by five-year periods of scientific production on total productivity in biomedicine and health sciences, Psychiatry and Neurology area, and second-generation antipsychotic drugs in Korea. Data from each five-year period refer to evolution over the previous period. The period of reference is 1992-96. Data are expressed in percentages. SGA: second-generation antipsychotic drug.

Table 2. Distribution of the journals in Bradford's zones

\begin{tabular}{cccc}
\hline Zones & $\begin{array}{c}\text { Number of } \\
\text { journals }\end{array}$ & $\begin{array}{c}\text { Number of } \\
\text { articles }\end{array}$ & $\begin{array}{c}\text { Bradford's } \\
\text { constants }\end{array}$ \\
\hline 1 & 1 & 36 & \\
2 & 1 & 35 & 1 \\
3 & 2 & 39 & 2 \\
4 & 3 & 35 & 1.5 \\
5 & 4 & 37 & 1.33 \\
6 & 6 & 38 & 1.5 \\
7 & 12 & 37 & 2 \\
8 & 24 & 36 & 2 \\
9 & 33 & 33 & \\
\hline
\end{tabular}

Total number of journals $=86$, Average number of articles $=36.22$, Average number of articles, excluding the last Bradford zone $=36.62$

higher (in the three consecutive five-year periods) compared to the global growth of Korean science in biomedicine and health, and to the specific field of Psychiatry and Neurology.

As regards to the scientific journals in which the SGA papers had been published, we applied the Bradford's model. The mean number of articles per Bradford zone was 47.79, though if we discarded the last zone, whose accuracy was obviously lower, the mean would be 51.46 . Table 2 shows the division into Bradford's areas of the papers in this study. The nucleus or first zone would be made up exclusively of the Progress in Neuro-Psychopharmacology and Biological Psychiatry, with 36 papers, and the second zone European Neuropsychopharmacology $(n=35)$. The rest of the journals analyzed are included in zones 3 to 9 . A total of 86 different journals were used to publish those papers analysed. To note, the 10 most used journals accounted for $53.37 \%$ of all papers in 
Table 3. The 10 journals with highest number of publications on second-generation antipsychotic drugs from Korea

\begin{tabular}{lccc}
\multicolumn{1}{c}{ Journal } & No documents & PI & IF* \\
\hline Progress in Neuro-Psychopharmacology and Biological Psychiatry & 36 & 11.04 & 2.877 \\
European Neuropsychopharmacology & 35 & 10.74 & 4.201 \\
Human Psychopharmacology Clinical and Experimental & 20 & 6.13 & 5.83 \\
International Journal of Neuropsychopharmacology & 19 & 3.68 & 3.607 \\
Clinical Psychopharmacology and Neuroscience & 12 & 3.68 & 3.37 \\
Journal of Cancer Education & 12 & 3.07 & 0.682 \\
Journal of Clinical Psychopharmacology & 11 & 3.857 \\
Psychiatry Investigation & 10 & 3.07 & 0.221 \\
Journal of Clinical Psychiatry & 10 & 2.76 & 5.023 \\
Psychiatry and Clinical Neurosciences & 9 & & 1.559 \\
\hline
\end{tabular}

*Journal Citation Report, 2010 (JCR, 2011). PI: participation index, IF: impact factor 2010

Table 4. Distribution of documents on SGAs in the world's 10 most productive countries in biomedicine and health sciences and South Korea for the period of 1993-2011

\begin{tabular}{llrrrc}
\hline & Country* & $\%^{*}$ & $\begin{array}{c}\text { Psy-Neurol } \\
(\%)\end{array}$ & SGAs (\%) & $\begin{array}{c}\text { SGAs/ } \\
\text { Psy-Neurol }\end{array}$ \\
\hline 1 & USA & 25.78 & 35.61 & 31.84 & 1.14 \\
2 & UK & 7.36 & 9.92 & 7.97 & 1.01 \\
3 & Japan & 6.62 & 6.82 & 3.27 & 0.61 \\
4 & Germany & 6.30 & 7.93 & 6.33 & 1.02 \\
5 & France & 4.55 & 4.93 & 3.46 & 0.89 \\
6 & China & 3.95 & 2.90 & 2.00 & 0.88 \\
7 & Italy & 3.87 & 4.76 & 4.59 & 1.23 \\
8 & Canada & 3.67 & 5.03 & 5.68 & 1.44 \\
9 & Spain & 2.69 & 2.90 & 3.93 & 1.73 \\
10 & Australia & 2.47 & 3.07 & 2.69 & 1.12 \\
& South Korea & 1.31 & 1.17 & 1.61 & 1.90 \\
\hline
\end{tabular}

*the world's 10 most productive countries in biomedicine and health sciences (and South Korea) for the period of 1993-2011, their productivity in the discipline of Psychiatry and Neurology; Total documents 1993-2011: 13,746,667; Total documents in Neurology \& Psychiatry Area 1993-2011:1,471,156. Psy-Neurol: area of focus in Neurology and Psychiatry, SGAs: second-generation antipsychotic drugs

this study.

Table 3 shows these 10 journals most used for the diffusion of scientific SGA papers by Korean authors and their corresponding IFs, according to the JCR of 2010, and the PI of the journals on total database in the analyzed period. The journals (Table 3) most extensively used for the diffusion of SGA papers have high IFs ( 6 of them having an IF being greater than 2 , and 4 an IF being greater than 4 ).

Manually classifying articles, we found that $54.61 \%$ of them belonged to the "clinical efficacy" group, $24.54 \%$ to the "tolerance and safety" group, $16.87 \%$ to the "experimental pharmacology" group, and $3.98 \%$ to the "not specified" group (main-

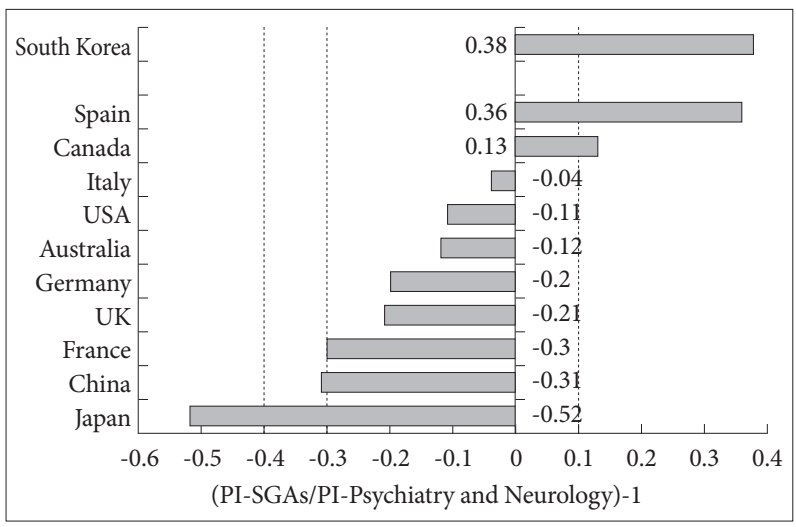

Figure 5. Relationship between production of scientific literature on SGAs and total production in the field of Psychiatry and Neurology in the world's 10 most productive countries in biomedicine and health sciences and South Korea. PI: participation index, SGAs: second-generation antipsychotic drugs.

ly, pharmacoeconomic analysis and articles of prescribing patterns). Clinical studies are mainly devoted to schizophrenia $(n=87)$ and bipolar disorder $(n=40)$, and to a lesser extent, to depressive disorders $(n=12)$ and dementia $(n=8)$.

The general contribution of Korean science, within this thematic area, represents a global PI of 1.61 with respect to world production in period analyzed. Table 4 shows that among the countries generating most significant SGA research, the USA (whose PI is 31.84), is most significant, followed by the United Kingdom (PI=7.97), Germany (PI=6.33), Canada (PI= 5.68), Italy ( $\mathrm{PI}=4.59)$ and Spain $(\mathrm{PI}=3.93)$.

If we consider the paper productivity of these countries in the field of Psychiatry and Neurology, only 2 (Spain and Canada) of the 10 largest producers in biomedicine and health sciences (in the period of 1993-2011), and South Korea devoted a higher percentage of attention to the SGA study (Figure 5). In the analysis of the correlation between PI and the per capita health expenditure of each of the countries with the highest scientific production in health sciences, the distribu- 


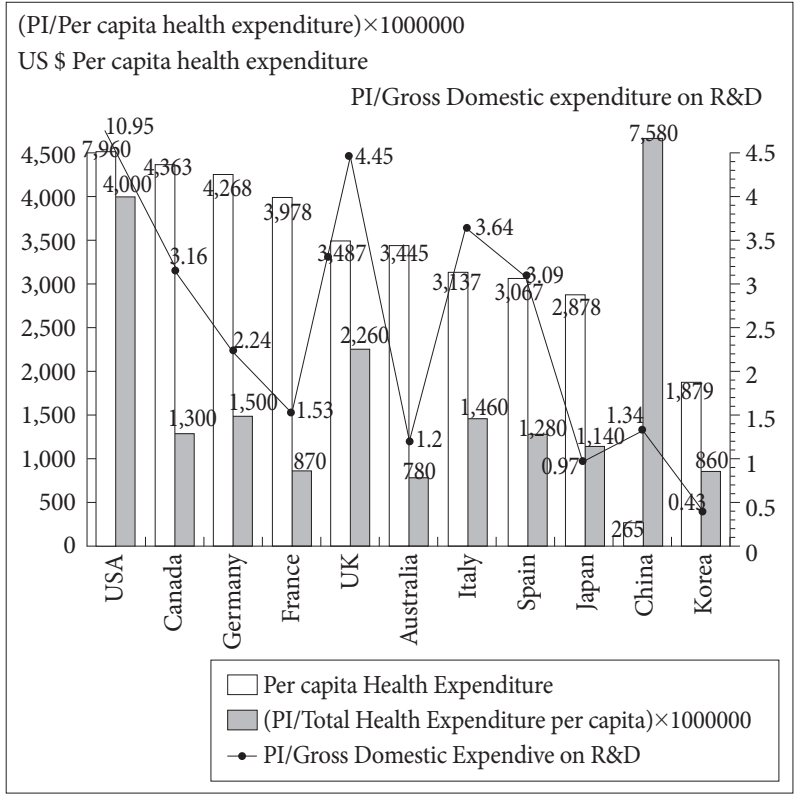

Figure 6. Per capita health expenditure and relationship between production of scientific literature on SGAs and per capita health expenditure and gross domestic expenditure on R\&D, in the world's 10 most productive countries in biomedicine and health sciences and South Korea. SGAs: second-generation antipsychotic drugs, R\&D: research and development, PI: participation index, PPP: purchasing power parity. Total health expenditure per capita PPP US $\$$ (data from the Organization for Economic and Co-operative Development [OECD] 2009). ${ }^{23}$ Japan and Australia; Data 2008; China: Total health expenditure per capita PPP Int \$ (data 2008). ${ }^{24}$; Gross domestic expenditure on R\&D (\%): Data OECD 2010, except USA and Japan (data 2009) and China (data 2007).

tion obtained was quite similar, except for China (Figure 6), although in this case it is an artifact due to the small Chinese per capita health expenditure (265 purchasing power parity Int \$).

Table 5 shows the most Korean productive institutions to produce SGA papers in this study. As it can be seen, $24.54 \%$ of total production was generated in Seoul National University Bundang Hospital, and St. Marys Hospital at The Catholic University of Korea College of Medicine. But the rankings here are solely based on the information given in the $\mathrm{AD}$ field in the EMBASE Biomedical Answer web database, i.e., we identified affiliated institutions of the author address of those SGA papers in this study.

\section{DISCUSSION}

Bibliometric studies constitute interesting tools for assessing the social and scientific importance of a given discipline over a specific time period. The term "bibliometrics" was introduced in 1969 by Alan Pritchard, to define the application of mathematical and statistical methods to the process of dissemination of written communication in the area of scientific disciplines, by means of quantitative analysis of the different
Table 5. Contribution of SGA papers from different institutions in Korea

\begin{tabular}{lc}
\hline \multicolumn{1}{c}{ Institution } & N \\
\hline $\begin{array}{l}\text { Seoul National University Bundang Hospital, } \\
\text { Chongrogu, Seoul }\end{array}$ & 45 \\
$\begin{array}{l}\text { St. Marys Hospital, Catholic University of Korea College } \\
\text { of Medicine, Bucheon }\end{array}$ & 35 \\
Chonnam National University Hospital, Gwangju & 22 \\
Korea University College of Medicine, Seongbuk-gu, Seoul & 22 \\
Catholic University of Korea, College of Medicine, Seoul & 20 \\
$\begin{array}{l}\text { Inje University, College of Medicine, Goyang } \\
\text { University of Ulsan College of Medicine, Asan Medical }\end{array}$ & 20 \\
Center, Seoul & 12 \\
$\begin{array}{l}\text { Ansan Hospital, Korea University, Ansan, Kyunggi } \\
\text { Naju National Hospital, Naju-si, Jeollanam-do }\end{array}$ & 12 \\
$\begin{array}{l}\text { Sungkyunkwan University School of Medicine, Jangan-gu, } \\
\text { Suwon, Gyeonggi-do }\end{array}$ & 8 \\
$\begin{array}{l}\text { Anam Hospital, Korea University College of Medicine, } \\
\text { Seongbuk-gu, Seoul }\end{array}$ & 8
\end{tabular}

SGA: second-generation antipsychotic drug, n: number of documents in the study database

aspects of this type of communication. ${ }^{25}$ These analyses permit an overview of the growth, size and distribution of the scientific literature related to a particular discipline, and the study of the evolution of not only the biomedical specialty, field of specialization or issue in question, but also the scientific production of an institution, country, author or research group. ${ }^{12}$ The utility of bibliometric analysis is obvious. It enables to monitor and to map the state of the art in researchers' respective fields, to trace and to track group or individual or scientific performance, and to back up the justification of research funding allocations, etc.

Taking into account these premises, the design of the present analysis allows us to make a global assessment of the growth of scientific literature in relation to SGAs in South Korea. In this regard, it should be stressed how the number of scientific publications has undergone exponential growth over the last 20 years, and especially after 2007, without evidence, up to the end of the period studied, of the process of saturation postulated by Price in his theory of expansion of scientific literature. ${ }^{20}$ These bibliometric data show a close correlation with the prescription data in this region (China, Hong Kong, Japan, Korea, Singapore and Taiwan), as revealed in the pharmacoepidemiological study of the Research on Asian Psychotropic Prescription (REAP) Project. The prescribing patterns in 2001, 2004 and 2008 showed a significant increase of the uses of SGAs (2001; 45.5\%, 2004; 64.7\%, 2008; 76.6\%). ${ }^{26,27}$

Precisely, the great development of the scientific literature on SGAs coincides with its approval for marketing by the US 
Food and Drug Administration (FDA) and other international regulatory agencies in the treatment bipolar disorder. Since 2004, other SGAs such as risperidone, quetiapine, ziprasidone, aripiprazole, and asenapine, etc. have been also approved for the treatment of manic episodes, and olanzapine and aripiprazole for relapse prevention in patients with bipolar disorder. ${ }^{28}$ Quetiapine is indicated as monotherapy for the acute treatment of depressive episodes associated with bipolar disorder, and olanzapine-fluoxetine combination for treating treatment-resistant major depressive disorder. ${ }^{28}$ Also aripiprazole was approved in 2007 by the FDA for treating treatmentresistant major depression as an add-on to an antidepressant. ${ }^{28}$ Likewise, with increasing multiple indications of SGAs, there have been also a steep growth of clinical trials using SGAs for various psychiatric disorders in Korea, currently about 100 clinical trials has been finished or actively recruiting patients based on the ClinicalTrial.gov database (http://clinicaltrials. gov). Finally, SGAs are also commonly used (and studied) in numerous off-label indications, such as toxic psychosis, agitation symptoms, tics, substance abuse disorders, etc. ${ }^{29,30}$ In this sense, there has been an important upsurge in the five-year period of 2002-06, coinciding with the period of official approval of the new SGAs and new indications for SGAs (bipolar disorder, depression, autism, etc.). In the individual analysis of the new SGAs, risperidone emerges as the agent most widely studied. But it is striking to note the increase in publications on clozapine since 2007 with the increase in the clinical use of this antipsychotic detected in Korea by the REAP project. ${ }^{31}$

Another aspect of interest in relation to scientific production that we analyzed is its quality of papers from Korea. To this end, we used the indicators of impact and excellence of the publications on the topic in question. The fact that such prestigious journals as Journal of Clinical Psychiatry (IF= 5.023), Journal of Clinical Psychopharmacology ( $\mathrm{IF}=4.857)$, International Journal of Neuropsychopharmacology (IF= 4.699), or European Neuropsychopharmacology ( $\mathrm{IF}=4.201$ ) published articles on SGAs from Korea is an important factor, indicating the relevance (both clinical and social) that this country has acquired in recent years. To note, among the 10 publications most widely used in Korea for the international divulgation on SGAs research, 6 journals are in the ranking of the most relevant in the field of Psychiatry (IF in 2010 being greater than 2).

Although some mid-2000s' studies suggested that only $1 \%$ of all scientific publications on Korea were mental health, ${ }^{9}$ our results confirm that during the period of 1993-2011, the percentage of papers in the area of Psychiatry and Neurology accounted for $9.55 \%$ of the total scientific production in Korea. As we have shown in recent studies, ${ }^{19}$ scientific research on SGAs is one of the fastest growing fields within the field of psychiatry. Similarly, some authors, also applying bibliometric tools, have reported the research activity in the field of schizophrenia as superior to that of other fields of psychiatry. ${ }^{32}$ These authors also suggest that the attraction of research on schizophrenia may have been positively affected by the clinical perception of the greater seriousness of the illness compared to other psychiatric pathologies. Moreover, Theander and Wetterberg report that the number of references on schizophrenia in MEDLINE has followed the general increase of medical publications, which accounts for $0.42 \%$ compared to the total medical literature in the period studied..$^{33}$

The two major English-speaking countries, USA and UK, head the ranking of producer countries, and between them generate over a third of total scientific production in this field (39.81\%). The fact that in these two countries are home to the pharmaceutical companies responsible for the development of SGAs (olanzapine - Eli Lilly, USA; risperidone and paliperidone - Janssen Pharmaceutica, USA; quetiapine - AstraZeneca, UK; ziprasidone - Pfizer, USA; and aripiprazole - BristolMyers Squibb/Otsuka Pharmaceutical Co., USA/Japan) may help explain this high PI.

Table 4 shows the data from the 10 most productive countries in biomedicine and health sciences and South Korea and compares the data for general productivity in the Psychiatry and Neurology discipline with productivity in the specific field of SGAs. It is worthy of note how some places, such as Spain, Canada, and South Korea sit near the top of the ranking for SGAs production (Figure 5), reflecting the special interest of these countries in research into these drugs. Other countries, such as the USA, Italy and Australia, maintain rates of productivity in SGA research that are in proportion with their global index for psychiatry. Contrariwise, it is interesting to note the lower relative interest in these drugs, within the context of their general production in psychiatry, of countries such as Japan, China, or France.

The correlation of scientific production in SGAs with the per capita health expenditure of each country offers us a parallel view of this phenomenon; in general, there is confirmation of the notion that the higher the spending on health, the greater the research production. In this regard, it should be made clear that a country's scientific production in a given field tends to reflect a science research and development policy begun some years before the period analyzed, and is not the fruit of particular economic circumstances. ${ }^{16,17}$ It is striking, however, to observe the low ratios of countries such as Australia, South Korea or France. Despite being recently the world's first 7 to meet the gross domestic product (GDP) per capita (PPP US\$29,997), South Korea has a health expenditure relatively low for developed countries (ranking 28; 6.9\% of GDP). In addition, only $6 \%$ of health care expenditures by 
the government health department are devoted to mental health. ${ }^{11}$ The correlation analysis between scientific production in SGAs and the gross domestic expenditure on R\&D located to Australia, Japan and Korea at the last three positions.

\section{Limitations and strengths of the study}

The readers are warned against over-interpreting the study findings because this study has three major limitations which are inherent to its bibliometric nature. ${ }^{34}$

First, not all the SGA papers from South Korea were included. This bibliometric study includes papers from EMBASE Biomedical Answer web. The criteria set by the databases themselves determine the subsequent development of the studied materials. ${ }^{12,35}$ Excluded are those papers on SGAs if authors do not put the SGA descriptors in the titles or key words of the papers, national or local journals that are not included in MEDLINE and Excerpta Medica, and those contributions at scientific conferences and meetings. ${ }^{14}$ In fact, there are many Korean-based neuropsychopharmacological journals affiliated with psychiatric and neurological academic societies in Korea, such as the Journal of Korean Neuropsychiatric Association, the Korean Journal of Psychopharmacology, the Korean Journal of Biological Psychiatry, and the Korean Journal of Biological Therapies, etc. Hence, we have to keep in mind that more papers regarding experimental and/or clinical papers of SGAs may exist in various neurosciences and clinical fields in Korea. In addition, Korea has English journals such as the Clinical Psychopharmacology and Neuroscience which is affiliated with Korean College of Neuropharmacology, which are not included in our search engines.

Second, in the AD (author address) section the descriptor South Korea, we included only those papers with Korean corresponding authors in this study. By the research design, we did not count those papers as Korean papers if those Korean authors are not addressing authors of the papers.

And third, the use of indicator impact factor to determine the merit or quality of scientific contributions is still debatable. The citation count may mean that the given topic is the study is "not yet mature" and is "in need of more studies." But it may not mean the work is more important than those papers which do not get many citations. Differing in those in the Europe and Asia, American universities do not use impact factor as much to measure the production of a faculty member.

Analyzing bibliometric information based on the proportions of industry-sponsored, pre- and post-marketing trials/ reports, and independent clinical trials should also provide more detailed trend toward collaboration between academy and pharmaceuticals.

In spite of the above-listed study limitations, bibliometric studies are useful in assessing the social and scientific relevance of a given discipline or field. ${ }^{13}$ Those studies constitute an effective complement for the opinions and judgments of experts in each field, giving useful and objective tools to evaluate the results of scientific activity, offering a more realistic view of the picture and an indication of trends, as well as predicting how it might evolve. ${ }^{35}$ For future bibliometric researches, it should be useful to extend the analysis of research outputs to incorporate the impact of biomedical research on healthcare and policy decision-making. It suggests potential useful avenues for future bibliometric research - the media and in medical education. Covering bibliometric studies of research papers by clinical guidelines will give more practical information to clinicians regarding real-world practice. More precise refinement of bibliometirc indicators should be further improved as well.

\section{Conclusion}

Keeping in mind of the above-listed limitations and strengths, we have been able to offer a picture of the representativeness and evolution of international research on SGAs in Korea, observing the parameters of quality and dissemination most commonly employed at an international level.

SGAs as a group of pharmaceutic class started to become number 1 in the market sale (US\$ 14.6 billion per year) in 2008 in the USA..$^{28}$ Any new SGA, as a commercial commodity, can easily become an instant "mega-drug" (by the definition of having the annual sale of US $\$ 500$ million) if it can occupy only $4 \%$ of market share in the USA..$^{28}$ Thus, research in this field will definitely continue to grow in the coming years. We need to bear in mind that the ideal antipsychotic drug has not yet been found, ${ }^{7}$ and that the need of treating many treatment-resistant patients is waiting to be met. ${ }^{36}$

Besides, SGAs have, and will continue to have, an ever-expanding range of clinical indications, both within the psychiatric ambit and outside it, to judge from the promising results obtained for the different pathologies with which they have been studied; ${ }^{29}$ in consequence, scientific production in relation to these drugs will certainly continue to be abundant, as is happening with the prescription patterns of SGA in this region.

\section{Acknowledgments}

This study was supported by a grant (UCJC 2012-01) of the Camilo José Cela University (I Convocatoria de Ayudas a la Investigación Competitiva).

\section{REFERENCES}

1. López-Muñoz F, Alamo C, Rubio G, Cuenca E. Half a century since the clinical introduction of chlorpromazine and the birth of modern psychopharmacology. Prog Neuropsychopharmacol Biol Psychiatry 2004; 28:205-208. 
2. López-Muñoz F, Alamo C, Cuenca E, Shen WW, Clervoy P, Rubio G. History of the discovery and clinical introduction of chlorpromazine. Ann Clin Psychiatry 2005;17:113-135.

3. López-Muñoz F, Álamo C. The consolidation of neuroleptic therapy: Janssen, the discovery of haloperidol and its introduction into clinical practice. Brain Res Bull 2009;79:130-141.

4. Shen WW. A history of antipsychotic drug development. Compr Psychiatry 1999;40:407-414.

5. Kane J, Honigfeld G, Singer J, Meltzer H. Clozapine for the treatmentresistant schizophrenic. A double-blind comparison with chlorpromazine. Arch Gen Psychiatry 1988;45:780-796.

6. Hippius H. A historical perspective of clozapine. J Clin Psychiatry 1999; 60(Suppl 12):22-23.

7. López-Muñoz F, Álamo C. Neurobiological background for the development of new drugs in schizophrenia. Clin Neuropharmacol 2011;34: 111-126.

8. Korean Neuropsychiatric Association. Annual Report 2011, Volume 27. Seoul: Korean Neuropsychiatric Association; 2011.

9. WHO and Ministry of Health and Welfare. WHO-AIMS Report on Mental Health System in Republic of Korea. Gwacheon: WHO; 2007.

10. Suh TW, Cho MJ, Kim JH, Kwak YS, Kim KK, Bae A, et al. 2005 The Central Mental Health Supporting Committee Report. Seoul: Ministry of Health and Welfare, Korean Institute for Health and Social Affairs, Central Mental Health Supporting Committee; 2006.

11. Hwang TY, Kim DH. Republic of Korea's Country Report. In: Asia-Pacific Community Mental Health Development Project. Melbourne: Asia Australia Mental Health (AAMH), 2008. p. 1-21.

12. Bordons M, Zulueta MA. Evaluation of the scientific activity through bibliometric indices. Rev Esp Cardiol 1999;52:790-800.

13. White HD, McCain KW. Bibliometric. Ann Rev Inf Sci Technol 1989;24: 119-186.

14. López-Muñoz F, Marín F, Boya J. Bibliometric evaluation of the Spanish scientific output in neurosciences. Analysis of the publication with international readership between 1984 and 1993. Rev Neurol 1996;24: 417-426.

15. López-Muñoz F, Alamo C, Rubio G, García-García P, Martín-Agueda B, Cuenca E. Bibliometric analysis of biomedical publications on SSRIs during the period 1980-2000. Depress Anxiety 2003;18:95-103.

16. López-Muñoz F, Vieta E, Rubio G, García-García P, Alamo C. Bipolar disorder as an emerging pathology in the scientific literature: a bibliometric approach. J Affect Disord 2006;92:161-170.

17. López-Muñoz F, Álamo C, Quintero-Gutiérrez FJ, García-García P. A bibliometric study of international scientific productivity in attentiondeficit hyperactivity disorder covering the period 1980-2005. Eur Child Adolesc Psychiatry 2008;17:381-391.

18. López-Muñoz F, García-García P, Sáiz-Ruiz J, Mezzich JE, Rubio G, Vieta E, et al. A bibliometric study of the use of the classification and diagnostic systems in psychiatry over the last 25 years. Psychopathology
2008;41:214-225.

19. López-Muñoz F, Shen WW, Moreno R, Molina JD, Noriega C, PérezNieto MA, et al. International scientific productivity on second-generation antipsychotic drugs in Taiwan: A bibliometric study. Taiwanese J Psychiatry 2012;26:114-129.

20. Price DJS. Little Science, Big Science. New York: Columbia University Press; 1963.

21. Bradford SC. Documentation. London: Crosby Lockwood; 1948.

22. Garfield E. Citation Indexing. Its Theory and Application in Science, Technology and Humanities. New York: Wiley; 1979.

23. Organization for Economic and Co-operative Development Health Division. OECD Health Data 2011 - Frequently Requested Data (June 30, 2011). Paris: OECD; 2011.

24. World Health Organization Department of Health Statistics and Informatics. World Health Statistics 2011 (May 13, 2011). Geneva: WHO; 2011.

25. Pritchard A. Statistical bibliography or bibliometrics. J Doc 1969;25: 348-369.

26. Chong MY, Tan CH, Shinfuku N, Yang SY, Sim K, Fujii S, et al. Prescribing antipsychotic drugs for inpatients with schizophrenia in Asia: comparison of REAP-2001 and REAP-2004 studies. Asia-Pac Psychiatry 2010;2:77-84.

27. Nakano W, Yoshimura R, Yang S. The characteristics of pharmacotherapy for inpatients with schizophrenia: A multicentre comparative study in Asia. Eur Neuropsychopharmacol 2010; 20(Suppl 3):S467-S468.

28. Shen WW. Clinical Psychopharmacology for the 21 Century, Third Edition (in Chinese). Taipei: Ho-Chi Publishing Company; 2011.

29. Fountoulakis KN, Nimatoudis I, Iacovides A, Kaprinis G. Off-label indications for atypical antipsychotics: A systematic review. Ann Gen Hosp Psychiatry 2004;3:4.

30. Mortimer AM, Shepherd CJ, Rymer M, Burrows A. Primary care use of antipsychotic drugs: an audit and intervention study. Ann Gen Psychiatry 2005;4:18.

31. Xiang YT, Wang CY, Si TM, Lee EH, He YL, Ungvari GS, et al. Clozapine use in schizophrenia: findings of the Research on Asia Psychotropic Prescription (REAP) studies from 2001 to 2009. Austral N Z J Psychiatry 2011;45:968-975.

32. Clement S, Singh S, Burns T. Status of bipolar disorder research. Bibliometric study. Br J Psychiatry 2003;182:148-152.

33. Theander SS, Wetterberg L. Schizophrenia in Medline 1950-2006: a bibliometric investigation. Schizophr Res 2010;118:279-284.

34. Johnson MH, Cohen J, Grudzinskas G. The uses and abuses of bibliometrics. Rep BioMed Online 2012;24:485-486.

35. Gómez I, Bordons M. Limitaciones en el uso de los indicadores bibliométricos para la evaluación científica. Política Científica 1996;46:21-26.

36. Molina JD, Jiménez-González AB, López-Muñoz F, Cañas F. Evolution of the concept of treatment-resistent schizophrneia: toward a reformulation for lack of an adequate response. J Exp Clin Med 2012;4:98-102. 